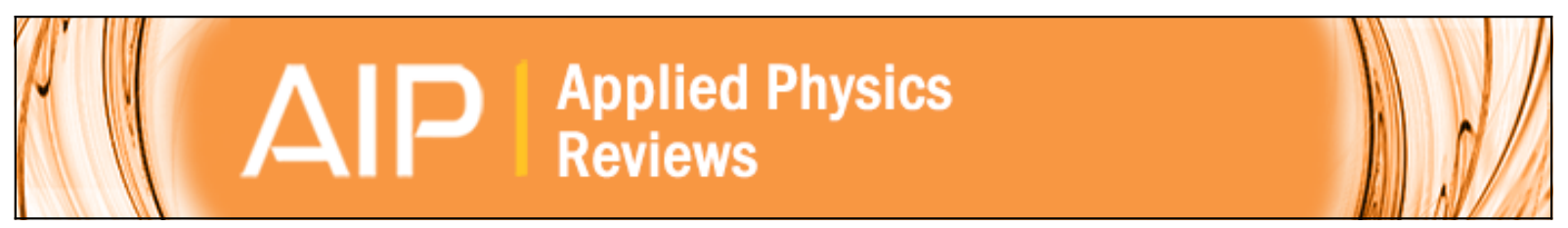

\title{
Radiofrequency heating of nanomaterials for cancer treatment: Progress, controversies, and future development
}

Xiaoming Liu, Hui-jiuan Chen, Xiaodong Chen, Yasir Alfadhl, Junsheng Yu, and Dongsheng Wen

Citation: Applied Physics Reviews 2, 011103 (2015); doi: 10.1063/1.4915002

View online: http://dx.doi.org/10.1063/1.4915002

View Table of Contents: http://scitation.aip.org/content/aip/journal/apr2/2/1?ver=pdfcov

Published by the AIP Publishing

\section{Articles you may be interested in}

Fundamentals and advances in magnetic hyperthermia

Appl. Phys. Rev. 2, 041302 (2015); 10.1063/1.4935688

Porous silicon nanoparticles as sensitizers for ultrasonic hyperthermia Appl. Phys. Lett. 103, 193110 (2013); 10.1063/1.4829148

Effects of core/shell structure on magnetic induction heating promotion in $\mathrm{Fe} 3 \mathrm{O} 4 / \mathrm{y}-\mathrm{Fe} 2 \mathrm{O} 3$ magnetic nanoparticles for hyperthermia

Appl. Phys. Lett. 103, 163104 (2013); 10.1063/1.4825270

Effect of the distribution of anisotropy constants on hysteresis losses for magnetic hyperthermia applications Appl. Phys. Lett. 103, 142417 (2013); 10.1063/1.4824649

Protein adsorption enhanced radio-frequency heating of silica nanoparticles Appl. Phys. Lett. 103, 043706 (2013); 10.1063/1.4816668

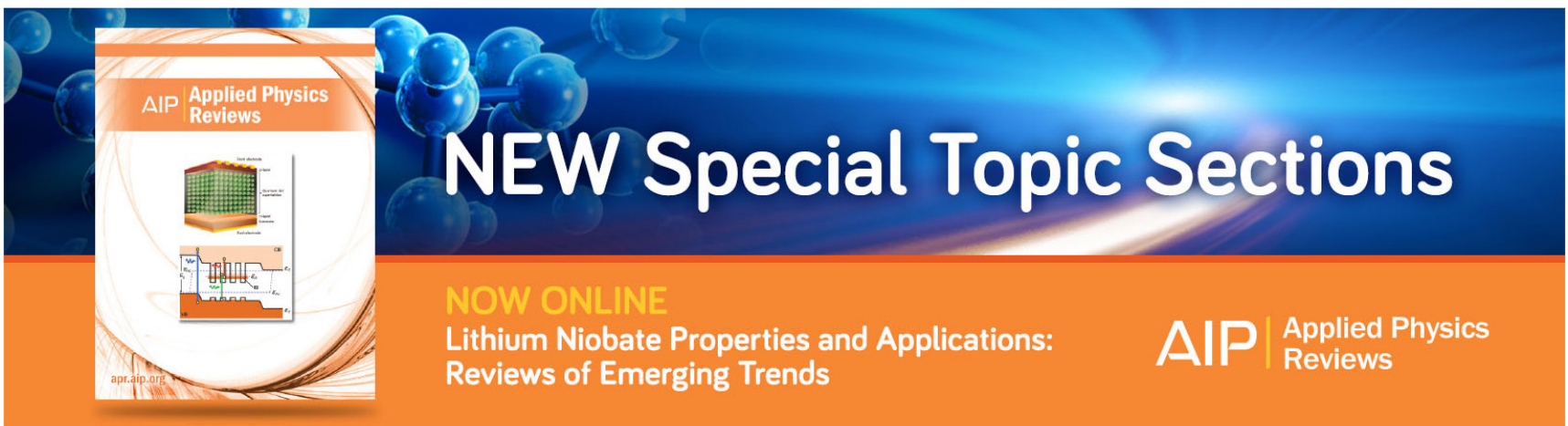




\title{
Radiofrequency heating of nanomaterials for cancer treatment: Progress, controversies, and future development
}

\author{
Xiaoming Liu, ${ }^{1,2, a)}$ Hui-jiuan Chen, ${ }^{3}$ Xiaodong Chen, ${ }^{2}$ Yasir Alfadhl, ${ }^{2}$ Junsheng Yu, ${ }^{1}$ \\ and Dongsheng Wen ${ }^{4,5)}$ \\ ${ }^{1}$ School of Electronic Engineering, Beijing University of Posts and Telecommunications, Beijing 100876, \\ China \\ ${ }^{2}$ School of Electronic Engineering and Computer Science, Queen Mary University of London, London E1 4NS, \\ United Kingdom \\ ${ }^{3}$ SYSU-CMU Shunde International Joint Research Institute, Shunde 510006, China \\ ${ }^{4}$ School of Chemical and Process Engineering, University of Leeds, Leeds LS2 9JT, United Kingdom
}

(Received 24 January 2015; accepted 25 February 2015; published online 20 March 2015)

\begin{abstract}
In recent years, the application of nanomaterials to biological and biomedicine areas has attracted intensive interest. One of the hot topics is the nanomaterial mediated radiofrequency (RF) hyperthermia or ablation, i.e., using RF fields/waves to heat tumor tissues treated with nanomaterials to destroy cancerous cells while minimizing the side-heating effect. However, there are currently many contradictive results reported concerning the heating effect of nanomaterials under a RF field. This paper provided a comprehensive review to nanomaterial mediated RF ablation from both experimental and theoretical aspects. Three heating mechanisms were discussed, i.e., laser heating, magnetic field heating, and electric field heating in RF spectrum, with the focus on the last one. The results showed that while diluted pure metallic nanoparticles could be heated significantly by a laser through the surface plasmon resonance, they cannot be easily heated by a RF electric field. Further studies are proposed focusing on nanoparticle structure and morphology, electromagnetic frequency and localized heating effect to pave the way for future development. C 2015 AIP Publishing LLC.
\end{abstract}

[http://dx.doi.org/10.1063/1.4915002]

\section{TABLE OF CONTENTS}

I. INTRODUCTION

II. NANOMATERIAL AIDED RF THERMAL

THERAPY

III. PHOTOTHERMAL ABLATION . . . . . . . . .

IV. ELECTRIC FIELD HEATING. . . . . . . . . .

A. Classical theory of electric heating .......

B. Theoretical models and their limitations....

1. The Joule model ................

2. Classical and quantum effects .........

3. Electrophoretical model ............

4. The aggregation effect $\ldots \ldots \ldots \ldots \ldots$

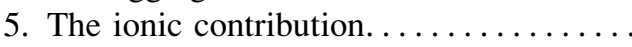

C. Limitations of the current heating models...

D. Possibilities to increase the electric field

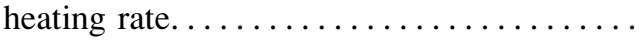

V. CONCLUSION...................

\section{INTRODUCTION}

The scale of nanomaterials is in the range of $1-100 \mathrm{~nm}$, which is physically on the edge of quantum mechanics

\footnotetext{
a)xiaoming_liu@bupt.edu.cn

b)d.wen@leeds.ac.uk
}

regime and biologically of the size of cellular components. ${ }^{1-3}$ Nanomaterials have many unique characteristics, for example, quantum size effect, size dependent properties, large surface-to-volume ratio, good biocompatibility, and easy surface functionalization with targeting biomolecules. In consequence, nanomaterials have been extensively investigated for various applications in biological and biomedicine areas, such as biosensing/bioimaging, ${ }^{4-6}$ drugdelivery, ${ }^{7-9}$ and nanomaterial mediated cancer diagnose and treatment. ${ }^{10-12}$ For instance, metal nanoparticles have been intensively studied for the application in bioimaging, due to that the scattering effect can be significantly enhanced by several orders of magnitude compared to conventional dyes. ${ }^{13,14}$ Moreover, a number of nanomaterials can be easily tailored by attaching biological groups/ligands, facilitating targeting specific cells, or delivering drugs. ${ }^{15,16}$

One of the applications is the nanomaterial mediated cancer treatment, which has been investigated world-wide. Generally speaking, the process of cancer treatment involving nanomaterials includes at least the following steps: (1) preparation of nanomaterials and/or loading drugs; (2) surface functionalization with targeting biological molecules (e.g., proteins and peptides); (3) injection and delivery of loaded nanomaterials; and (4) cancer treatment by releasing loaded drug or heating of nanomaterials via an external source. The method of using RF field as the heating source 
to kill cancer cells is usually referred to as the RF ablation (RFA) or RF hyperthermia method. For RFA, it aims to deliver RF energy to the tumor sites to produce significant regional temperature rise (i.e., $>42^{\circ} \mathrm{C}$ ), leading to irreversible thermal damage to cancer cells. ${ }^{17,18}$

Conventional RFA or RF hyperthermia involves a probe or antenna inserting into tumor to deliver RF energy, ${ }^{19-21}$ which is invasive and difficult for deep-in-body organs. The difficulties include (1) low RF delivery efficiency due to the large absorption by tissues and (2) large side effect due to the heating of health cells especially under a high electric field. It is possible to address these issues in the RFA technique by the aid of loaded nanomaterials. It is envisaged that nanomaterials could absorb electromagnetic (EM) energy much more significantly than their bulk counterparts, i.e., with higher specific absorption rates (SAR). Subsequently, tissues incubated with nanomaterials shall exhibit faster temperature rise than those without. In consequence, it is possible to significantly increase the temperature of nanomaterial incubated cancerous tissues at a safe EM field level, while limiting the detrimental effect to normal tissues.

To reach such a goal, a number of laboratory studies have been conducted using various nanomaterials (gold nanoparticles, carbon nanotubes, cobalt nanoparticles, etc.) at different $\mathrm{EM}$ frequencies $(200 \mathrm{kHz}, 13.56 \mathrm{MHz}$, $2.45 \mathrm{GHz}$, infrared (IR), etc.). ${ }^{22-32}$ An apparent preclinical success is the photothermal hyperthermia, where tissues treated with nanomaterials are illuminated with IR or UVvisible lasers. The success is, however, constrained by the fact that IR or UV-visible lasers have limited penetration depth to tissues, usually on the order of several centimeters that is not suitable for deep-in-body tumors. In contrast, lower frequency EM, RF, for example, can penetrate into tissues much deeper. Therefore, nanomaterial mediated RF hyperthermia is proposed and investigated for potential cancer treatment. Currently, two methods have already been identified, electric heating and magnetic field heating. The heating mechanisms of the two methods differ from each other. Electric field heating of bulk material originates from the dielectric or Ohmic loss, ${ }^{33,34}$ while magnetic field heating is due to the hysteresis phenomenon or relaxation property that relates to the imaginary part of permeability. ${ }^{35,36}$ For magnetic field heating, nanomaterials of suitable magnetic properties are required.

Unfortunately, many controversies have been reported especially regarding the heating mechanism in the RF range, and the technology is still at its infancy. Experiments conducted in different research groups showed rather contradictive results. While some studies demonstrated that nanomaterials can be heated significantly, ${ }^{22-26}$ showing much higher SARs, others suggested that the abnormal high heating effect was originated from the ionic impurities rather than the nanomaterials. ${ }^{27,28}$ There are still strong debates if nanomaterials can be heated by a RF/microwave field, and if so what are the mechanisms. Different to the IR/visible light laser heating, which is due to the surface plasmon resonance (SPR) phenomenon, the mechanism of electric field heating of nanomaterials in the RF/microwave range is still not fully understood. To shed some light on this problem, this paper conducted an overview of the electromagnetic heating of nanomaterials in order to promote in-depth discussions and pave the way for its future applications. Particularly, the heating mechanisms were discussed in detail, including laser heating, magnetic, and electric field heating, with a focus on the last one. In addition, a few possibilities of enhancing the heating effect were proposed for future studies. Furthermore, during the discussion, some key aspects were compared and discussed such as the EM frequency and material properties. It shall be noted that although laser is not in the RF range, it is no harm to include it here for the purpose of comparison and clarification of the heating mechanism in the RF range. The biological aspects of nanomaterials were not covered in this work and interested readers are directed to relevant review papers such as Refs. 37-39.

This paper is organized as follows: Sec. II gives a brief introduction to the process of nanomaterial mediated RFA; Sec. III discusses briefly the heating mechanisms of laser; and Sec. IV is concentrated on the electric field heating, with a critical analysis on the reported theoretical and experimental work.

\section{NANOMATERIAL AIDED RF THERMAL THERAPY}

The basic process of nanomaterial aided RFA or RF hyperthermia is illustrated in Fig. 1. First, suitable nanoparticles are surface functionalized with targeting biomolecules and injected into the circulation system. Once the loaded nanoparticles reach the cancer cells or accumulate in the surrounding areas, EM fields/waves are applied. Heat generated due to the absorption of EM energy diffuses from heated nanoparticles to cancer tissues, leading to rapid regional temperature rise that causes irreversible damage to cancer cells.

The key factor of such a method depends on how much EM energy that the nanoparticles can absorb and dissipate to the cells. Various EM frequencies have been utilized for material heating, such as IR/visible light and RF/microwave. Of these frequencies, three methods can be broadly categorized: electric field heating, magnetic heating, and laser heating (NIR, IR, visible, and ultra-violet lasers). The representative examples of EM fields/waves are summarized in Table I.

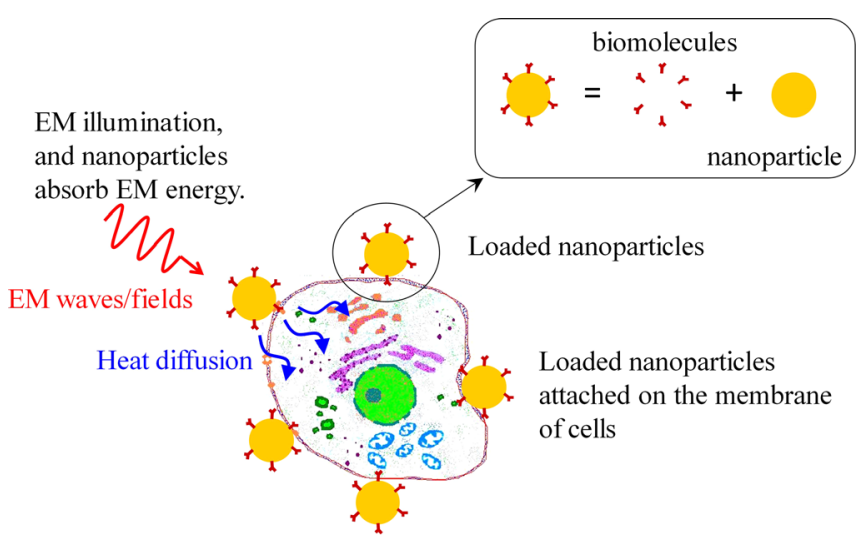

FIG. 1. Schematic view of RF hyperthermia: Nanoparticles are loaded with targeting biomolecules and heated by EM fields/waves, causing damage to cancer cells. 


\begin{tabular}{|c|c|c|c|c|c|c|}
\hline Methods & Reference & Frequency & Materials $^{\mathrm{a}}$ & Concentration & Apparatus & Observations \\
\hline \multirow[t]{18}{*}{ Electric field } & 25 & $13.56 \mathrm{MHz}$ & $\mathrm{CNT}$ & $5-500 \mathrm{mg} / \mathrm{l}$ & Kanzius system & CNT heating rate $0.8 \mathrm{~K} / \mathrm{s}$ at $600 \mathrm{~W}$; DI-water heating rate $0.2 \mathrm{~K} / \mathrm{s}$ \\
\hline & 22 & $13.56 \mathrm{MHz}$ & GNP & $1.1-67 \mu \mathrm{mol} / 1$ & Kanzius system & $67 \mu \mathrm{m} / \mathrm{l} \mathrm{GNP}$ suspension heating rate $0.9 \mathrm{~K} / \mathrm{s}$ at $600 \mathrm{~W}$ \\
\hline & 23 & $13.56 \mathrm{MHz}$ & GNP & $13 \mathrm{nmol} / \mathrm{l}$ & Kanzius system & Heating rate $\sim 0.3 \mathrm{~K} / \mathrm{s}$ at $100 \mathrm{~W}$; DI-water $\sim 0.025 \mathrm{~K} / \mathrm{s}$ at $100 \mathrm{~W}$ \\
\hline & 40 & $13.56 \mathrm{MHz}$ & GNP & $\ldots$ & Kanzius system & $\begin{array}{l}\text { Exposure of cells to a noninvasive RF field produced nearly } 100 \% \text { cyto- } \\
\text { toxicity in cells treated with the cetuximab-conjugated gold nanoparticles, } \\
\text { but significantly lower levels of cytotoxicity in the two control groups }\end{array}$ \\
\hline & 24 & $13.56 \mathrm{MHz}$ & GNP & $1.4-36 \mathrm{ppm}$ & Kanzius system & $\begin{array}{l}1.4 \mathrm{ppm} \text { GNP had } 35 \mathrm{~K} \text { increase in } 2 \mathrm{~min} \text {; DI-water had } 2 \mathrm{~K} \text { increase in } \\
2 \mathrm{~min}, 600 \mathrm{~W}\end{array}$ \\
\hline & 41 & $10 \mathrm{MHz}-50 \mathrm{GHz}$ & GNP & $\ldots$ & $\begin{array}{l}\text { Resonating chamber under } \\
\text { mild magnetic stirring }\end{array}$ & $\begin{array}{l}\text { Peptide-gold nanoparticles selectively attached to b-amyloid protein }(\mathrm{Ab}) \\
\text { amyloidogenic aggregates were irradiated with microwave }\end{array}$ \\
\hline & 42 & $13.56 \mathrm{MHz}$ & GNP & $100 \mathrm{nmol} / \mathrm{l}$ & Kanzius system & $\begin{array}{l}\text { Panc-1 cells demonstrated increased apoptosis with decreased viability } \\
\text { after treatment with cetuximab-conjugated AnNPs and RF field exposure }\end{array}$ \\
\hline & 43 & $13.56 \mathrm{MHz}$ & GNP & $100 \mathrm{nmol} / \mathrm{l}$ & Kanzius system & $\begin{array}{l}\text { In vitro study, Panc- } 1 \text { had a viability of } 46 \% \text {, while Cama- } 1 \text { cell had a } \\
\text { viability of } 92 \% \text { after } 200 \mathrm{RF} \text { heating for } 2 \mathrm{~min}\end{array}$ \\
\hline & 44 & $13.56 \mathrm{MHz}$ & GNP & $25-100 \mu \mathrm{g} / \mathrm{ml}$ & Kanzius system & $\begin{array}{l}\text { In vitro study, Panc-1 had a viability of } 39.4 \% \text {, while Cama- } 1 \text { cell had a } \\
\text { viability of } 93.7 \% \text { after } 200 \text { RF heating for } 4 \mathrm{~min}\end{array}$ \\
\hline & 45 & $13.56 \mathrm{MHz}$ & GNP & $100 \mathrm{mcg} / \mathrm{ml}$ & Kanzius system & $\begin{array}{l}\text { Cells treated with C225-AuNP accumulated } 6.07 \text { times higher intracellular } \\
\text { thermal dose than the untreated controls over initial } 4 \mathrm{~min} \text { of RF exposure }\end{array}$ \\
\hline & 46 & $13.56 \mathrm{MHz}$ & GNP & $250-2000 \mathrm{mg} / \mathrm{l}$ & Kanzius system & $\begin{array}{l}\text { Heating rate for } 5 \mathrm{~nm} \text { GNPs } 0.45 \mathrm{~K} / \mathrm{s} \text {. Only GNPs smaller than } 10 \mathrm{~nm} \text { can } \\
\text { be heated }\end{array}$ \\
\hline & 27 & $13.56 \mathrm{MHz}$ & GNP & 0.006 wt. $\%$ & Kanzius system & Heating is due to supernatant, not due to GNPs. Size of GNPs: $50 \mathrm{~nm}$ \\
\hline & 26 & $13.56 \mathrm{MHz}$ & GNP & $25-55 \mu \mathrm{g} / \mathrm{ml}$ & $\begin{array}{l}\text { Cascaded multi-level } \\
\text { resonating system }\end{array}$ & $\begin{array}{l}0.4-2 \mathrm{~K} / \mathrm{s} \text { heating rate for GNPs; GNP mediated RF heating can enhance } \\
\text { cell killing }\end{array}$ \\
\hline & 28 & $13.56 \mathrm{MHz}$ & GNP & $1.1-67 \mu \mathrm{mol} / 1$ & Waveguide & Heating is due to ions, not due to GNPs. Size of GNPs: $5-20 \mathrm{~nm}$ \\
\hline & 30 & $2.45 \mathrm{GHz}$ & GNP & $13.2-26.4 \mu \mathrm{g} / \mathrm{ml}$ & Microwave generator & $\begin{array}{l}\text { GNP incubated samples produced } 2.5^{\circ} \mathrm{C} \text { higher temperature rise compared } \\
\text { to control group }\end{array}$ \\
\hline & 31 & $2.45 \mathrm{GHz}$ & GNP & $50 \mu \mathrm{g} / \mathrm{ml}$ & Microwave oven & $\begin{array}{l}\text { Application of gold nanoparticles can enhance the lethal effect of low } \\
\text { power microwave in a very short exposure time }(5 \mathrm{~s}) \text {. }\end{array}$ \\
\hline & 47 & $0.35 \mathrm{MHz}$ & PtNP GNP & $0-10 \mathrm{ppm}$ & Insulating current system & $\begin{array}{l}\text { Both PtNP and GNP can be heated, PtNPs generate } 50 \% \text { higher heat than } \\
\text { GNPs }\end{array}$ \\
\hline & 48 & $3 \mathrm{GHz}$ & GNP & $\cdots$ & $\cdots$ & $\begin{array}{l}\text { The increased fluorescence for the gold nanoparticle-conjugated nanoma- } \\
\text { chines is not due to bulk heating of the solution, but is caused by the } \\
\text { presence of the gold nanoparticles and their interaction with the RF field }\end{array}$ \\
\hline \multirow[t]{6}{*}{ Magnetic Field } & 29 & $200 \mathrm{kHz}$ & GNP & $0.13-1.6 \mathrm{ppm}$ & Magnetic coil & Heating rate $0.002 \mathrm{~K} / \mathrm{s}$ for $1.6 \mathrm{ppm}$ \\
\hline & 49 & $600-800 \mathrm{kHz}$ & $\begin{array}{l}\text { Magnetite and } \\
\text { gold nanoparticles }\end{array}$ & 4 wt. $\%$ & Magnetic coil & $\begin{array}{l}\text { Local temperature measurement in the vicinity of electromagnetically } \\
\text { heated magnetite and gold nanoparticles }\end{array}$ \\
\hline & 50 & $191-385 \mathrm{kHz}$ & $\mathrm{FeCo}-\mathrm{Au}$ & $11 \mathrm{mg} / \mathrm{ml}$ & $\ldots$ & The heating rate is particle size an frequency dependent \\
\hline & 51 & $260 / 357 \mathrm{kHz}$ & $\mathrm{Fe}_{3} \mathrm{O}_{4}$ & & $\ldots$ & $\begin{array}{l}\text { Magnetic nanoparticles can be applied to cancer treatment in combination } \\
\text { with biological molecules }\end{array}$ \\
\hline & 52 & $357 \mathrm{kHz}$ & $\mathrm{Fe}$ & $10 \mathrm{pg} \mathrm{Fe} / \mathrm{cell}$ & $\cdots$ & $\begin{array}{l}\text { Radio frequency treatment required higher loading }(>10 \mathrm{pg} \mathrm{Fe} / \mathrm{cell}) \text { and } \\
\text { longer duration }(30 \mathrm{~min}) \text { when compared to laser to accomplish cell } \\
\text { destruction ( } 50 \% \text { viability at } 10 \mathrm{pg} \mathrm{Fe} / \mathrm{cell})\end{array}$ \\
\hline & 53 & $100 \mathrm{kHz}$ & Ferrite NP & 1 wt. $\%$ & $\cdots$ & $\begin{array}{l}\text { The SAR for our ac magnetic field presents a clear dependence on the } \\
\text { diameter of the nanoparticles, with a maximum SAR }=48 \mathrm{~W} / \mathrm{g} \text { for } 15 \mathrm{~nm}\end{array}$ \\
\hline
\end{tabular}




\begin{tabular}{|c|c|c|c|c|c|c|}
\hline Methods & Reference & Frequency & Materials $^{\mathrm{a}}$ & Concentration & Apparatus & Observations \\
\hline \multirow{14}{*}{ Laser } & 54 & $\ldots$ & $\mathrm{Au}_{102}(\mathrm{pMBA})_{44}$ & $100 \mu \mathrm{M}$ & $\ldots$ & $\begin{array}{l}\text { Magnetic heating shows temperature rise, while } 13.56 \mathrm{MHz} \text { heating does } \\
\text { not show any observable heating effect }\end{array}$ \\
\hline & 55 & $40 \mathrm{MHz}$ & $8 \mathrm{~nm}$ Fe-doped GNP & $14 \mathrm{mg} / \mathrm{ml}(3.7 \mu \mathrm{M})$ & $\ldots$ & $100 \mathrm{~A} / \mathrm{m}, \mathrm{SAR}: 1.84 \mathrm{~W} / \mathrm{g}$, temperature increase by $20^{\circ}$ in $300 \mathrm{~s}$ \\
\hline & 56 & $\ldots$ & $\begin{array}{c}2-25 \mathrm{~nm} \mathrm{Fe}_{3} \mathrm{O}_{4} \\
\mathrm{Fe}_{3} \mathrm{O}_{4}-\mathrm{PEG} \\
\mathrm{Fe}_{3} \mathrm{O}_{4}-\mathrm{OA}\end{array}$ & $2-20 \mathrm{mg}$ in $5 \mathrm{ml}$ & Magnetic coil & Temperature increased by $30^{\circ}$ within $10 \mathrm{~min}$ \\
\hline & 57 & $400 \mathrm{kHz}$ & Magnetite & $21 \mathrm{mg} / 299 \mathrm{~mm}^{3}$ & $\ldots$ & SAR data of different magnetite particle types ranged from 3 to $211 \mathrm{~W} / \mathrm{g}$ \\
\hline & 58 & $195-266 \mathrm{kHz}$ & $\mathrm{CoFe}_{2} \mathrm{O}_{4}$ & $20 \mathrm{mg} / \mathrm{ml}$ & Magnetic coil & $\mathrm{CoFe}_{2} \mathrm{O}_{4}$ nanoparticles show reasonable heating effect in magnetic field \\
\hline & 59 & $287 \mathrm{kHz}$ & $\mathrm{Fe}_{3} \mathrm{O}_{4}$-liposome & $0.03 \mathrm{mg} / \mathrm{ml}$ & Magnetic coil & SAR up to $100 \mathrm{~W} / \mathrm{g}$ at RF field strength $(H f)$ of $10^{5} \mathrm{kA} / \mathrm{m} / \mathrm{s}$ \\
\hline & 60 & $820 \mathrm{~nm}$ & Gold-silica nanoshell & 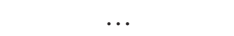 & NIR laser & Average tumor heating in nanoshell-treated tissue can be up to $60 \mathrm{~K}$ \\
\hline & 61 & $835 \mathrm{~nm}$ & Au@pNIPAM & $\ldots$ & Laser & $\begin{array}{l}\text { The size range and the tendency to shrink upon increasing the laser power } \\
\text { in the optical trap or by increasing the temperature }\end{array}$ \\
\hline & 62 & $355,400 \mathrm{~nm}$ & GNP & $1.6 \mathrm{mM}$ & Laser & $\begin{array}{l}\text { Highest efficiency for bubble formation will be expected as long as the } \\
\text { laser pulse remains around nanosecond limit }\end{array}$ \\
\hline & 63 & $532 \mathrm{~nm}$ & GNP & $\ldots$ & Laser & $\begin{array}{l}\text { Focal heating of Au-NP injected into a subcutaneous infected wound is ef- } \\
\text { ficacious and safe, and bypasses the need for antibiotics }\end{array}$ \\
\hline & 64 & $532 \mathrm{~nm}$ & GNP & $\ldots$ & Visible light laser & $\begin{array}{l}\text { The temperature of single particle }(40 \text { and } 100 \mathrm{~nm}) \text { can reach } 200 \mathrm{~K} \text { within } \\
50 \mathrm{~ns} \text { after the illumination of a laser of } 18 \mathrm{~mJ} / \mathrm{cm}^{2}\end{array}$ \\
\hline & 65 & $655 \mathrm{~nm}$ & GNP & $150 \mu \mathrm{M}$ & Visible light laser & $\begin{array}{l}0.5 \mathrm{~W} \text { laser heating. Aggregated particles show more temperature rise than } \\
\text { dispersed particles }\end{array}$ \\
\hline & 66 & $808 \mathrm{~nm}$ & $\begin{array}{l}\text { Gold nanoshell, } \\
\text { Gold nanorods }\end{array}$ & $\ldots$ & NIR laser & $\begin{array}{l}\text { The nanoshells generated more heat, per nanoparticle, than nanorods. The } \\
\text { gold nanorods had higher photothermal efficiency than the gold nanoshells }\end{array}$ \\
\hline & 67 & $495-710 \mathrm{~nm}, 1064 \mathrm{~nm}$ & GNP & $\ldots$ & IR laser & $\begin{array}{l}\text { The surface temperature elevation of nanoparticles can reach } 200 \mathrm{~K} \text { under } \\
0.8 \mathrm{~W} \text { laser illumination }\end{array}$ \\
\hline
\end{tabular}

aNP stands for gold nanoparticle, CNT is short for carbon nanotube, PtNP is Platium nanoparticles. All materials are at the nanoscale. 
The three heating methods in Table I are illustrated schematically in Fig. 2. Laser heating is realized through directing laser beam to tumor where nanoparticles are incubated. Magnetic fields are usually generated by magnetic coils of several turns and uniform magnetic field is achieved in the central part of the coil, where the samples are placed. Electric field can be generated between two electrodes via an alternative current (AC) source. In general, nearly uniform field can be produced between two parallel plates and samples are normally placed in between.

The heating mechanisms of the three methods are different from each other. The absorption of laser light is usually caused by the SPR, which can be explained by the Mie's theory. The magnetic heating of nanoparticles of magnetic properties is well established, either due to the hysteresis
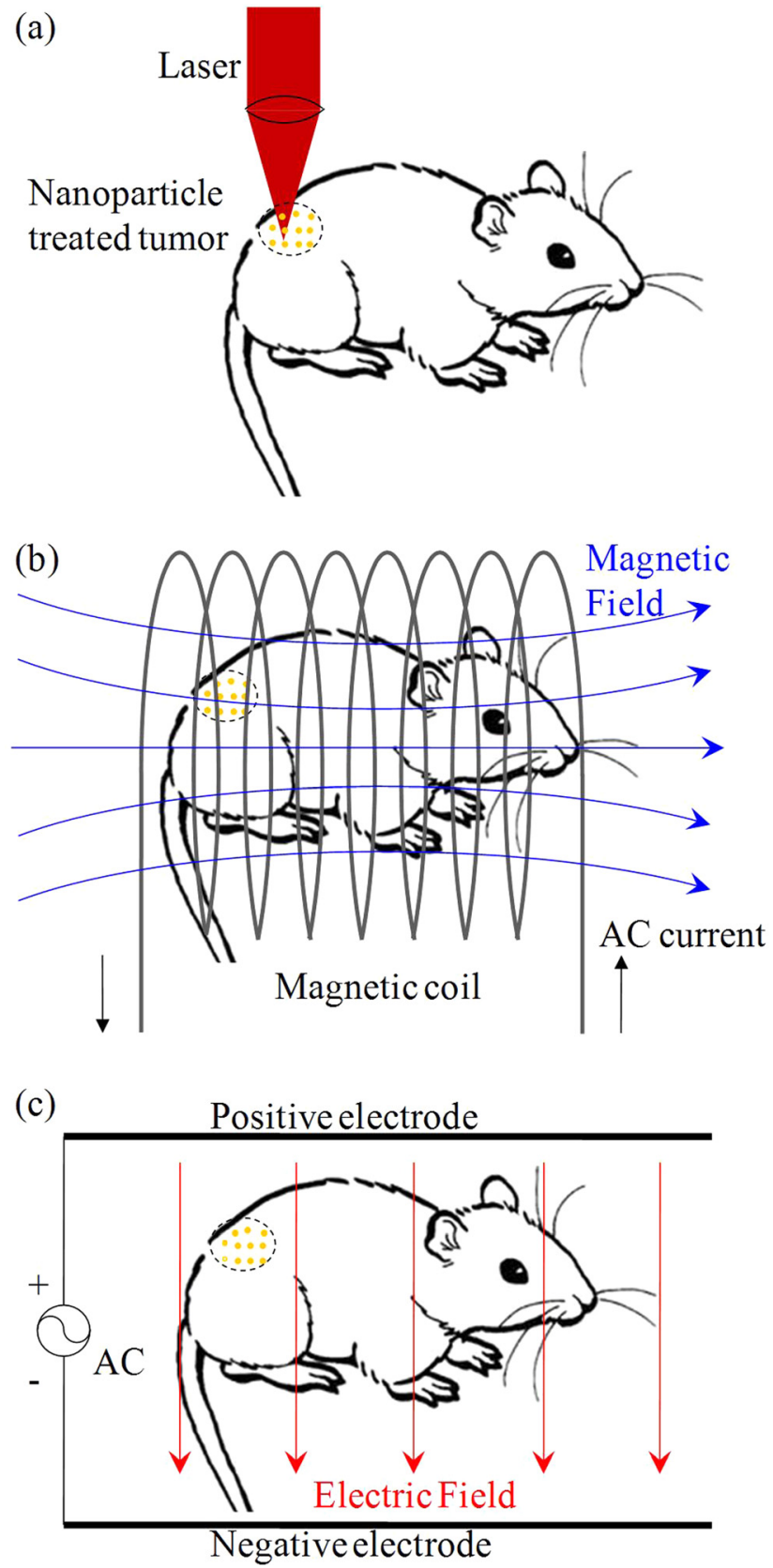

FIG. 2. Illustration of the three major heating methods: (a) Laser heating, (b) magnetic field heating, and (c) electric field heating. loss or the relaxation process. We will focus on the electric heating of nanoparticles under a RF field, as discussed in depth in Secs. III and IV.

\section{PHOTOTHERMAL ABLATION}

The heating effects of nanoparticles in the IR to visible light range can be largely explained by the SPR phenomenon, which is the collective oscillation of electrons in a solid stimulated by an incident light. Normally, this phenomenon occurs when the periphery of particles is comparable to the wavelength of light. The scattering and absorption of light by small particles can be quantified by the Mie's theory, ${ }^{18-20}$ in terms of their extinction, scattering, and absorption efficiencies, $Q_{e x t}, Q_{s c a}$, and $Q_{a b s}$. For homogeneous spheres, they are expressed as

$$
\begin{gathered}
Q_{e x t}=\frac{2}{x^{2}} \sum_{n=1}^{\infty}(2 n+1) \operatorname{Re}\left(a_{n}+b_{n}\right), \\
Q_{s c a}=\frac{2}{x^{2}} \sum_{n=1}^{\infty}(2 n+1)\left(\left|a_{n}^{2}\right|+\left|b_{n}^{2}\right|\right), \\
Q_{a b s}=Q_{e x t}-Q_{s c a}, \\
a_{n}=\frac{m \psi_{n}(m x) \psi_{n}^{\prime}(x)-\psi_{n}(x) \psi_{n}^{\prime}(m x)}{m \psi_{n}(m x) \xi_{n}^{\prime}(x)-\xi_{n}(x) \psi_{n}^{\prime}(m x)}, \\
b_{n}=\frac{\psi_{n}(m x) \psi_{n}^{\prime}(x)-m \psi_{n}(x) \psi_{n}^{\prime}(m x)}{\psi_{n}(m x) \xi_{n}^{\prime}(x)-m \xi_{n}(x) \psi_{n}^{\prime}(m x)},
\end{gathered}
$$

where $m$ is the ratio of refractive index of the sphere $n_{s}$ to that of the surrounding medium $n_{m}, x$ is the size parameter given as $2 \pi n_{m} R / \lambda$, and $\psi_{n}$ and $\xi_{n}$ are the Riccati-Bessel functions. The Mie's theory is in essence a solution to the Maxwell's equations. The SPR, denoted by a wavelength $\lambda_{\max }$, describes where the extinction efficiency peaks. By applying the Mie's theory, the heating of nanoparticles using lasers can be reasonably explained. Since the particle is much smaller than the wavelength, quasi-static approximation can be employed, leading to the Rayleigh approximation. The scattering and absorption coefficients can therefore be simplified to

$$
\begin{aligned}
Q_{s c a} & =\frac{8}{3} x^{4}\left|\frac{m^{2}-1}{m^{2}+2}\right|^{2}, \\
Q_{a b s} & =4 x \operatorname{Im}\left(\frac{m^{2}-1}{m^{2}+2}\right) .
\end{aligned}
$$

In consequence, the SPR wavelength can be largely estimated through Eqs. (6) and (7) as the refractive index is wavelength dependent.

Quite a few theoretical investigation has been intensively conducted (Refs. 68 and 69), as schematically shown in Fig. 3. When an ultrafast laser pulse illuminates on the nanoparticles, free electrons absorb the energy of photons, leading to an increase in kinetic energy. At this stage, these electrons are in a state of non-equilibrium distribution of energy. The equilibrium distribution is achieved through electron-electron relaxation at the order of $10-100$ fs. Later 


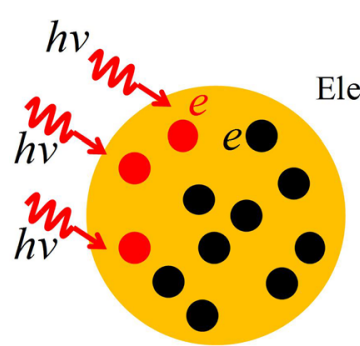

Electrons absorb energy from photons $\sim 100 \mathrm{fs}$
Electron-Electron

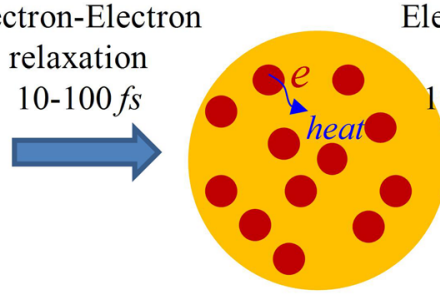

Electron-phonon

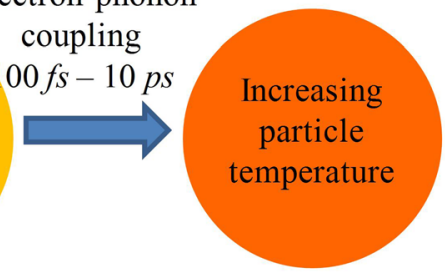

FIG. 3. The process of laser heating process of nanoparticles and tissues where NP stands for nanoparticles.

Nanoparticle diffuse heat to surrounding tissues.
Phonon-phonon

coupling

$1 p s-1 n s$

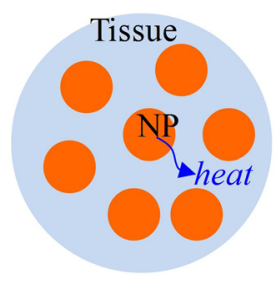

ps -1 ins

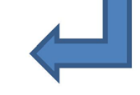

on, electron-phonon coupling takes effect and increases the particle temperature, which happens approximately between $100 \mathrm{fs}$ and $10 \mathrm{ps}$. Following the particle temperature increase, energy exchange between the particle and its surrounding medium begins to take place through phonon-phonon coupling, which is on the order of $1 \mathrm{ps}-1 \mathrm{~ns}$ and eventually causes temperature rise in surrounding medium.

Experimentally, there are a number of pre-clinical examples that have manifested the potential power of nanoparticles mediated photothermal ablation. For instance, Hirsch $^{60}$ successfully demonstrated gold-silica nanoshells mediated photothermal therapy using an $820 \mathrm{~nm}$ NIR. It was found that human breast carcinoma cells incubated with nanoshells in vitro had undergone photothermally induced morbidity on exposure to NIR light, while cells without nanoshells displayed no loss in the viability after the NIR illumination. Many groups have also conducted in vitro trials utilizing gold-silica nanoshells, showing promising therapeutic efficacy. ${ }^{61-67}$

Though in theory laser heating is well established, ${ }^{70,71}$ the nature of low penetration depth of laser light limits its wide applications. Hirsch investigated the temperature change of NIR-irradiated tumors with and without nanoshells at depths of $2.5,3.75,5.0$, and $7.3 \mathrm{~mm}$ beneath the apical tissue surface (see Fig. 5 in Ref. 60). It clearly showed that the heating rate decreased significantly with the increase of the depth. Particularly, when nanoshells were incubated at a depth of $7.3 \mathrm{~mm}$, there was no observable increase in the heating rate compared with the control group. Optical fiber might be introduced during an operation to circumvent the tissue absorption issue, such a scheme, however, is still of an invasive nature. $^{72}$

\section{ELECTRIC FIELD HEATING}

\section{A. Classical theory of electric heating}

Magnetic field is another method to heat nanomaterial for cancer treatment. Magnetic heating of nanoparticles was investigated as early as 1970 s with a focus on magnetic nanoparticles. The operating frequency of magnetic heating normally lies in the range of several kilohertz to several megahertz. Alternating magnetic fields can be easily generated in such a frequency range. Moreover, magnetic fields in such frequency range are more penetrable into human body. For practical applications, magnetic particles are generally dispersed into water, which is often referred to as magnetic nanofluids. The heating properties and mechanisms of magnetic nanofluids have been intensively investigated. ${ }^{29,49-59,73,74}$ The heating of magnetic nanofluids are originated from several reasons: (1) hysteresis loss; (2) Néel relaxation; (3) Brownian relaxation; (4) eddy current loss; and (5) ferromagnetic resonance. The details of these mechanisms are not discussed here since many review papers are available, such as Ref. 73 .

Comparing to the former two methods, the most controversial heating phenomenon of nanomaterials is the electric field heating. The pathway of electric field heating of nanoparticles has been reviewed in details by Collins et al. ${ }^{75} \mathrm{~A}$ simple chronology diagram of the representative investigations in recent years is organized in Fig. 4.

In 2007, the Kanzius machine (i.e., a RF device operating at $13.56 \mathrm{MHz}$ ) was reported to be able to heat carbon nanotube, ${ }^{25}$ and which could be utilized for cancer treatment. Later on, a few in vitro investigations showed great potential of this method. ${ }^{22,23}$ In 2009, size-dependent RF heating of GNPS was studied, ${ }^{24}$ which however was proved incorrect later on as most of the heating was due to the impurities in the dispersion. Theoretically, Hanson and Patch ${ }^{76}$ investigated the RF heating of nanoparticles, and showed that by the classical theory, it was lossy dielectric particles that could be heated maximally at a very low conductivity (see Fig. 3 in Ref. 76). In 2010, there were several papers published based on the Kanzius system. ${ }^{41-44}$ In spite of the success of the Kanzius system, the controversy began in 2011, when an experimental work based on the Kanzius system ${ }^{27}$ and a theoretical work ${ }^{77}$ were published. Li reported that the heating was not due to GNPs, but due to the ionic heating originated from the impurities inside the fluid. ${ }^{27}$ Hanson systematically investigated the heating mechanisms but concluded that none of them supported the electric heating of 


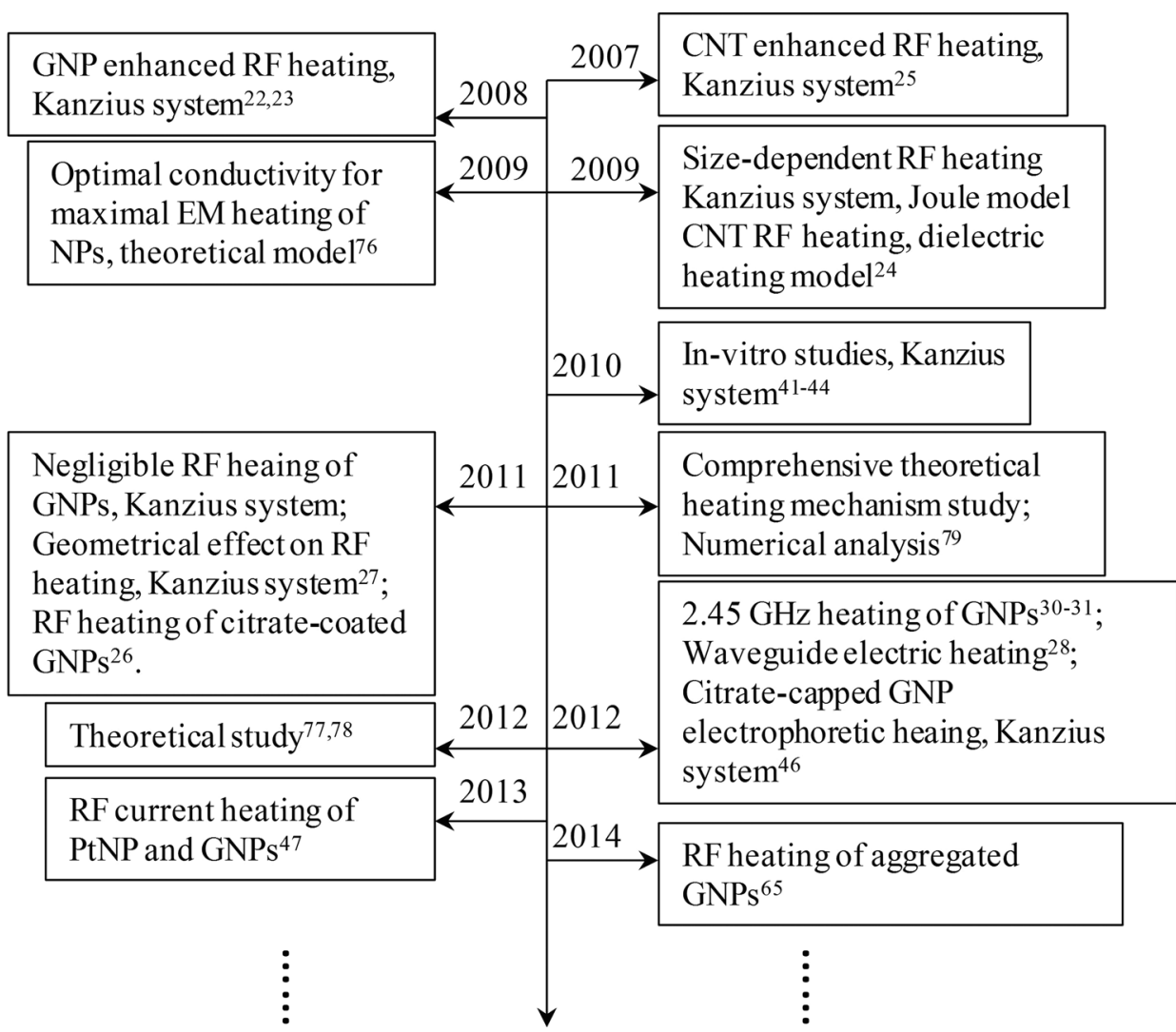

FIG. 4. A simple chronology diagram of electric field heating of GNPs for hyperthermia treatment.
GNPs. ${ }^{77}$ Pearce and Cook also concluded from their numerical model that GNPs could not be heated by a RF electric field. ${ }^{79}$ It has to be mentioned that, when one mentions magnetic heating, it does not necessarily mean there is no electric heating, and vice versa. It essentially means that magnetic heating or electric heating dominates the phenomenon. In 2012, Liu $^{28}$ reported an experimental work showing similar results as reported in Ref. 27. Particularly, Hanson ${ }^{77}$ and Sassaroli ${ }^{78}$ considered a number of mechanisms and came to the conclusion that naked GNPs cannot be heated by a RF electric field. Later on, $\mathrm{Corr}^{46}$ proved that citrate-capped GNPs can be heated through the electrophoretic effect. In 2013, San reported that electric current can be used to heat GNPs and PtNPs. ${ }^{47}$ In 2014, Liu reported that aggregated GNPs cannot be heated by the $13.56 \mathrm{MHz}$ RF electric field. ${ }^{65}$

In addition to $13.56 \mathrm{MHz}$, other frequencies are also investigated, for instance, $2.45 \mathrm{GHz} .^{30,31}$ However, microwave is not a very good option due to water-rich contents in human body. Water is a very good medium to absorb microwave energy, the principle of which is widely used in microwave cooking. Therefore, operating in this frequency range may cause an uncontrollable temperature rise.

There were many in vitro studies demonstrating the clinical effect of GNP incubation and RF radiation. ${ }^{41-44}$ Statistically, the combined treatment could kill up to $90 \%$ cancer cell. However, it is in an urgent need to clarify if the cell death was caused by the hyperthermia effect or not.

Through the classical theories, electric heating of material can be largely classified into two groups, i.e., dielectric heating and Joule heating. If the conductivity is a real number, then the gradient of the average energy flux density can be derived as

$$
\begin{aligned}
\nabla \cdot \vec{S}_{a v}= & \frac{1}{2} \nabla \cdot\left(\vec{E} \times \vec{H}^{*}\right) \\
= & \frac{1}{2} \vec{H}^{*} \cdot(\nabla \times \vec{E})-\frac{1}{2} \vec{E} \cdot\left(\nabla \times \vec{H}^{*}\right) \\
= & \frac{1}{2} \vec{H}^{*} \cdot\left(-j \omega \mu_{0} \mu_{r} \vec{H}\right)-\frac{1}{2} \vec{E} \cdot\left(\vec{J}^{*}-j \omega \varepsilon_{0} \varepsilon_{r}^{*} \vec{E}^{*}\right) \\
= & -\frac{1}{2} j \omega \mu_{0} \mu_{r}|\vec{H}|^{2}-\frac{1}{2}\left(-j \omega \varepsilon_{0} \varepsilon_{r}^{*}+\sigma^{*}\right)|\vec{E}|^{2} \\
= & \frac{1}{2} j \omega\left(\varepsilon_{0} \varepsilon_{r}^{\prime}|\vec{E}|^{2}-\mu_{0} \mu_{r}^{\prime}|\vec{H}|^{2}\right) \\
& -\frac{1}{2} \omega\left(\mu_{0} \mu_{r}^{\prime \prime}|\vec{H}|^{2}+\varepsilon_{0} \varepsilon_{r}^{\prime \prime}|\vec{E}|^{2}+\frac{\sigma}{\omega}|\vec{E}|^{2}\right),
\end{aligned}
$$

where the following equations are applied:

$$
\left\{\begin{array}{l}
\nabla \times \vec{H}^{*}=\vec{J}^{*}+\frac{\partial \vec{D}^{*}}{\partial t}=\sigma^{*} \vec{E}^{*}-j \omega \varepsilon_{0} \varepsilon_{r}^{*} \vec{E}^{*} \\
\nabla \times \vec{E}=-\frac{\partial \vec{B}}{\partial t}=-j \omega \mu_{0} \mu_{r} \vec{H} .
\end{array}\right.
$$

The imaginary part of Eq. (8) is the stored energy in electric and magnetic fields, while the real part is the dissipated energy of the studied medium. It can be seen that dielectric heating originates from the imperfection of dielectric media, while Joule heating from Ohmic loss is due to the conductive current. This is what the classical electromagnetic theory indicates. But the classical theory may not be able to explain the recently reported experimental results, as explained below.

\section{B. Theoretical models and their limitations}

As mentioned in Secs. II and III, a few work showed that nanoparticles (such as GNPs and CNTs) can greatly 
increase their SARs by using the Kanzius machine. ${ }^{22,23,25}$ It was argued that nanoparticles absorb electromagnetic energy, which causes temperature increase of the fluid due to the heat diffusion. Such work has promoted much debate on whether GNPs can be heated by electric field and by what mechanisms they are heated. Many theoretical models have been investigated, as summarized in Table II.

\section{The Joule model}

One of the models is the Joule heating model, ${ }^{24}$ which treats GNPs as conductors having constant cross sections

$$
I^{2} R=\sigma(\omega) \cdot\left[a \cdot d \cdot|\vec{E}|^{2}\right]
$$

where $\sigma(\omega)$ is the Drude model conductivity, $a$ is the crosssectional area of the GNP, $d$ is the diameter, and $|\vec{E}|$ is the field strength in nanoparticles. The heating rate, in consequence can be written as

$$
\frac{d T}{d t}=N \cdot \frac{\sigma(\omega) \cdot a \cdot d \cdot|\vec{E}|^{2}}{v \cdot C_{w}},
$$

where $N$ is the number of GNPs, $v$ is the volume of the dispersion, and $C_{w}$ is the specific heat capacity of water. The authors of Refs. 22 and 23 used this model to obtain the heating rate of the dispersion of $100 \mathrm{~nm}$ diameter GNPs of $1.9^{\circ} \mathrm{C} / \mathrm{s}$, which was in fair agreement with the measurement $2.8^{\circ} \mathrm{C} / \mathrm{s}$. However, it has to be pointed out that the electric field should be the one in GNPs rather that in water. The authors obviously calculated the heating rate using the field strength in the host water, $|\vec{E}|=200 \mathrm{~V} / \mathrm{m}$. The field strength in a metallic particle, however, is several orders of magnitude smaller than that in the host water. Furthermore, the factor $\mathrm{Nad} / \mathrm{v}$ in (16) is 1.5 times the volume fraction. Since the volume fractions were the same for all GNP dispersions, the heating rate should not show any size-dependent behavior according to this model. However, the experiment suggested the other way. Therefore, the Joule heating model could not explain the results successfully.

\begin{tabular}{|c|c|}
\hline Reference & Mechanisms/models investigated or proposed \\
\hline 76 & $\begin{array}{l}\text { Relative small conductivity causes optimum } \\
\text { electromagnetic heating }\end{array}$ \\
\hline 77 & $\begin{array}{l}\text { Classical Mie theory; coated nanoparticles; nonlocal } \\
\text { electron surface effects; phonon effect; aggregation effects }\end{array}$ \\
\hline 24 & Joule heating model \\
\hline 27 & Ionic contribution; magnetic heating \\
\hline 28 & Ionic contribution; dielectric heating \\
\hline 78 & $\begin{array}{l}\text { Dielectric relaxation; electrophoretic effect; } \\
\text { ionic contribution; aggregation effects }\end{array}$ \\
\hline 26 & Circuit model \\
\hline 46 & Electrophoretic effect; dielectric model \\
\hline 65 & Aggregation effect \\
\hline 79 & Dipole and polarization; clustering effect; collision model \\
\hline 80 & Dielectric heating \\
\hline 81 & Geometrical effects \\
\hline
\end{tabular}

TABLE II. A summary of electric heating mechanisms.
Moreover, the temperature rise of DI-water was observed as $5^{\circ} \mathrm{C}$ in Ref. 24, which was several orders of magnitude higher than the theoretical prediction

$$
d T=\frac{\sigma(\omega) \cdot|\vec{E}|^{2}}{2 \rho \cdot C_{w}} t,
$$

where $\rho$ is the density of water and t is the heating time. As the theoretical value of the conductivity of water at $13.56 \mathrm{MHz}$ is of the order of $10^{-4} \mathrm{~S} / \mathrm{m},{ }^{82}$ the water temperature rise in $2 \mathrm{~min}$ should be at the order of $10^{-4}{ }^{\circ} \mathrm{C}$, which was hardly noticeable in the experiments. To be consistent with the measured water rise of $5^{\circ} \mathrm{C}$, the field strength should be much higher than the given value of $|\vec{E}|=200 \mathrm{~V} / \mathrm{m}$. Indeed, the field strength was later on measured by the same group, ${ }^{46}$ showing that the electric field in Ref. 24 was incorrectly estimated.

As it stands now, the Joule heating model has been discarded by the researchers in this area. ${ }^{76}$ But it is the first work try to explain the phenomenon.

\section{Classical and quantum effects}

The first representative theoretical work of RF heating of nanoparticles was Hanson's analysis, ${ }^{76}$ where the role of the conductivity was investigated for different shapes. The theoretical work, starting from the classical EM theory, predicted that the optimal conductivity for RF heating could be very low. Several particle shapes have been investigated, such as rod, sphere, and coated sphere, as shown in Fig. 5.

In Hanson's model, ${ }^{76}$ the presence of nanoparticles reshapes the field distribution. Particularly important is that the dielectric constant of the material under the investigation plays a key role in determining the field distribution in nanoparticles. It is worth to emphasize that the field strength in the particles is critically different from the applied EM field. Hanson's model was accurate in reflecting this and considering the influence of particle shapes and dielectric properties, which were in agreement with the boundary conditions of the electric field. This model in essence predicted the heating effects from the classical EM theory.

Later on in another work, ${ }^{77}$ Hanson systematically analyzed several mechanisms, including both classical and quantum effects, and concluded that none of these absorption mechanisms, nor any combination of them, could increase temperatures at the rates reported in Refs. 22 and 23. In Ref. 77 , the influence of nonlocal electronic surface effects (electron spillout and surface roughness) were considered based on the classical Mie theory through the modification of the effective dielectric permittivity. It showed that noninteracting spherical metal nanoparticles could not be responsible for the heating observed in Refs. 22 and 23. Furthermore, the absorption of the host medium was studied, showing that in all cases involving metal nanoparticles, the absorption and subsequent heating were due to the absorbing host medium, irrespective the presence of spherical nanoparticles. The observation was supported by two independent experiments. ${ }^{27,28}$ However, needle-like objects such as carbon nanotubes or elongated ellipsoidal particles maintained a 
(a)

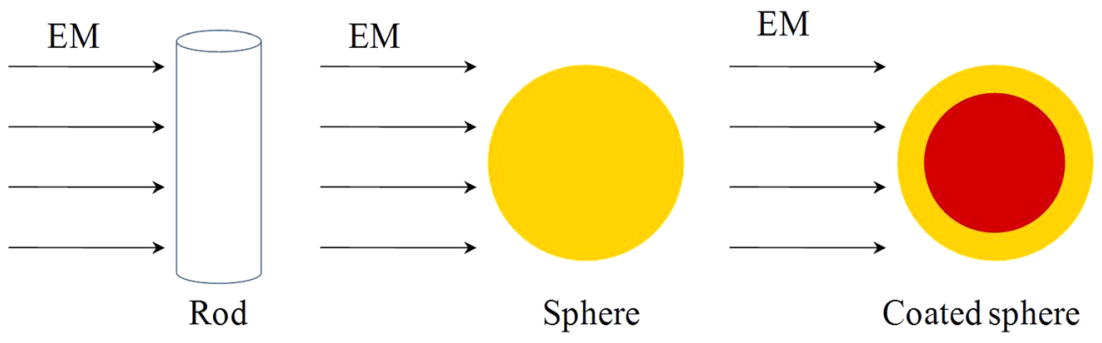

(b)

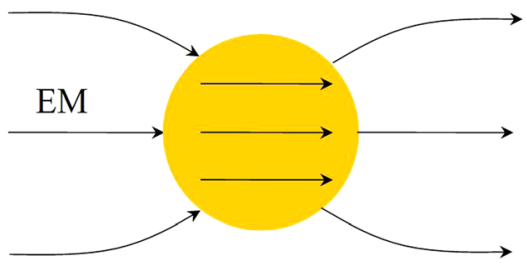

Sphere

strong radial near-field in the vicinity of the tube ends (e.g., lightning-rod effect), which could significantly enhance absorption in a conductive host. Such predictions agreed with the experimental study in Ref. 80, which showed that when carbon nanotubes were mixed with tissue mimicking materials, the relative permittivity and the loss factor were increased. The experiments at microwave range showed that the heating rates of carbon nanotubes treated tissue increased by nearly $50 \%$ at a concentration of $0.22 \mathrm{wt}$. \%. The significance of Ref. 77 is that it predicted what mechanisms were not and what mechanism were possible to cause EM heating.

\section{Electrophoretical model}

Another theoretical work by Sassaroli ${ }^{78}$ is also of considerable interest. Several possible mechanisms have been discussed in this paper, including the long-wave approximation (Mie theory), the relaxation effects in gold colloidal, dielectric loss by weak electrolyte solution, electrophoretic phenomenon, and so on. Mie theory indicated that the attenuation was dominated by the absorption of the medium with a much smaller effect due to the particles. The analysis from the Maxwell-Wagner theory also reached a similar conclusion, i.e., the dielectric losses were mainly due to the absorption in the medium especially in the low $\mathrm{MHz}$ range. The electric double layer affected the conductivity of the particle, but its effect in increasing the absorption in the suspension seems to be rather modest. However, the electrophoretic movement of charged nanoparticles was identified as a key factor for the increased absorption observed at RF, as analyzed below.

If charged particles were exposed to an electric field

$$
E=E_{0} e^{j \omega t},
$$

the movement of the particle can be described in the first approximation by the equation

$$
m \frac{d v}{d t}+\beta v=q E
$$

where $m$ is the mass, $v$ is the velocity, $q$ is the particle charge, $\beta$ is the friction constant $\beta=6 \pi \mu_{f} a$, and $\mu_{f}$ is the viscosity coefficient of the host medium. If $v=v_{0} e^{j \omega t}$, the equation can be written as

$$
\begin{gathered}
v_{0}=\frac{q E_{0}}{\beta} \frac{1}{1+j \omega \tau}, \\
\tau=\frac{m}{\beta},
\end{gathered}
$$

the electrophoretic current density is given by

$$
J=N q v_{0} e^{j \omega t}
$$

where $N$ is the number of particles per unit volume. Generally

$$
\begin{gathered}
J=\bar{\sigma}_{\text {flow }} E \\
\bar{\sigma}_{\text {flow }}=\bar{\sigma}_{\text {flow }}^{\prime}+j \bar{\sigma}_{\text {flow }}^{\prime \prime}=\frac{N q^{2}}{\beta} \frac{1}{1+j \omega \tau}, \\
\bar{\varepsilon}_{\text {flow }}=\bar{\varepsilon}_{\text {flow }}^{\prime}-j \bar{\varepsilon}_{\text {flow }}^{\prime \prime}=\frac{\bar{\sigma}}{j \omega \varepsilon_{0}}, \\
\left\{\begin{array}{l}
\bar{\varepsilon}_{\text {flow }}^{\prime}=-\frac{N q^{2}}{\beta \varepsilon_{0}} \frac{\tau}{1+(\omega \tau)^{2}} \\
\bar{\varepsilon}_{\text {flow }}^{\prime \prime}=\frac{N q^{2}}{\beta \omega \varepsilon_{0}} \frac{1}{1+(\omega \tau)^{2}} .
\end{array}\right.
\end{gathered}
$$

Therefore, the effect of electrophoresis can be mathematically incorporated into the effective dielectric permittivity. Based on this model, it was found that the eletrophoretic movement (see Fig. 9 in Ref. 78) affected significantly the dielectric loss for high particle concentrations, suggesting that the eletrophoretic movement was an important factor for concentrated dispersions. Following this line, Corr et al. ${ }^{46}$ investigated the electrophoretic heating of citrate-capped gold nanoparticles and suggested that the heating can be modeled using the electrophoretic oscillation of charged 


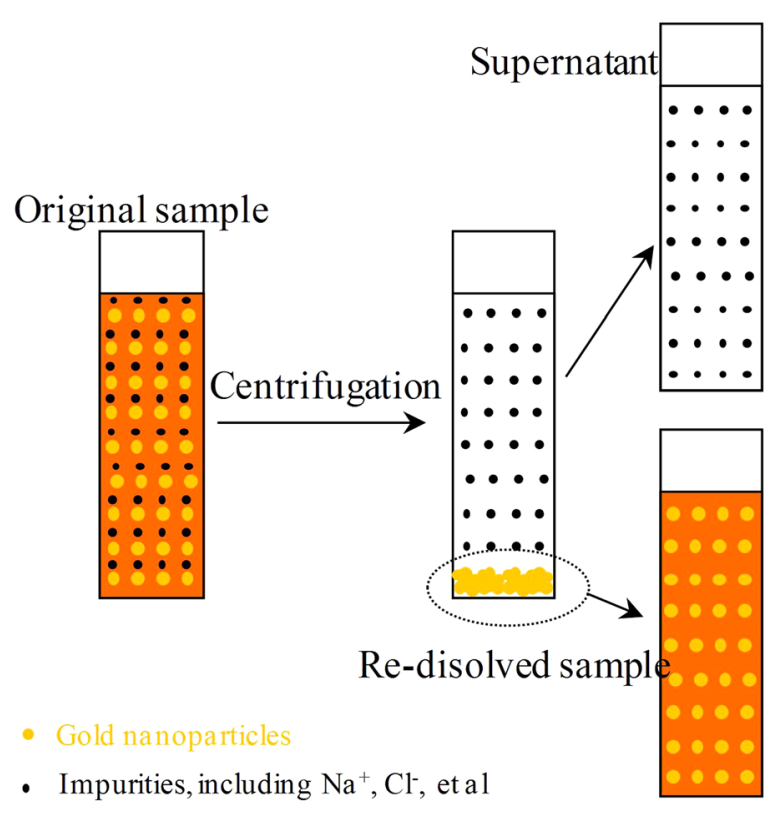

FIG. 6. The process of separation of GNPs from the original sample. Drawn from the description of Ref. 27.

gold nanoparticles in response to a time-varying electric field

$$
E_{M}=\frac{1}{30} \mu_{0}^{2} \sigma R^{5} \omega^{2} H_{0}^{2}
$$

For the case of a $50-\mathrm{nm}$ GNP exposed to $13.56 \mathrm{MHz}, 25 \mathrm{~W}$ $\mathrm{RF}$ power $\left(\mathrm{H}_{0}=1 \mathrm{~A} / \mathrm{m}\right)$, the amount of heat generation was calculated to be of $10^{-28} \mathrm{~W}$ order. The work of Kruse could be also caused by the electrophoretic effect. ${ }^{26}$

\section{The aggregation effect}

Many authors have mentioned the effect of aggregation $^{77-79}$ and evidences have shown that aggregated nanoparticles could increase the absorption of IR wave. ${ }^{83,84}$ The possible reasons may be due to the electrical field enhancement between adjacent particles. ${ }^{85}$ However, the enhanced absorption in IR range does not suggest that the same would happen in the RF range. Indeed, Liu has conducted a comprehensive study on the effect of aggregation on the heating rate at $13.56 \mathrm{MHz}$, which showed that the particle aggregation did increase the heating rate in the visible light region but had no significant effect in the RF range. ${ }^{65}$

One possible reason for the low heating effect at the RF range is that the size of aggregated particles are still too smaller comparing to the operating wavelength to cause any significant heating. But for laser heating, the aggregation would increase particle size and enhance the field effect, resulting higher heating rates.

\section{The ionic contribution}

Ionic contribution is another possible factor affecting the heating of nanofluids. The presence of ions increases the effective conductivity of a nanofluid, which may contribute to the heating significantly. However, the contribution from the conductivity is very complicated. Liu et al. suggested the possible modification of field distribution due to the change of boundary condition and dielectric properties. ${ }^{86}$ Experimentally, Liu et al. showed that the measured results could be explained by Hanson's model. ${ }^{28,86}$ In addition, the sample holder could also modify boundary condition that attenuated the field strength. ${ }^{81}$ Considering that the presence of ions modifies both the conductivity and the dielectric properties, the contribution of ionic heating has to be carefully treated. Different to nanoparticles, the effect of ions heating is through the modification of effective properties of the dispersion.

Indeed as revealed by Li et al. ${ }^{27}$ and Liu et al. ${ }^{28}$ independently, the supernatant sample dominated the heating effects. In Ref. 27, GNPs were centrifugally separated from the original sample and re-diluted to DI water, as shown in Fig. 6. It was found that these re-diluted samples could not be heated significantly. In contrast, the supernatant solution could be heated as fast as the original sample.

Liu also compared the measurement between impurified and purified samples, as shown in Fig. $7 .^{28,87}$ It was found that impurified sample can be heated with limited temperature rise, less than 1 centigrade, but the purified samples could not produce any observable heating within the accuracy of the measurement. The dielectric property measurement indicated that the effective conductivity of impurified samples was significantly higher than purified ones. To prove that the heating was due to the increase in effective conductivity, sodium chloride solution of the same effective conductivity was prepared and heated, which showed a similar temperature rise as the impurified GNP dispersions.

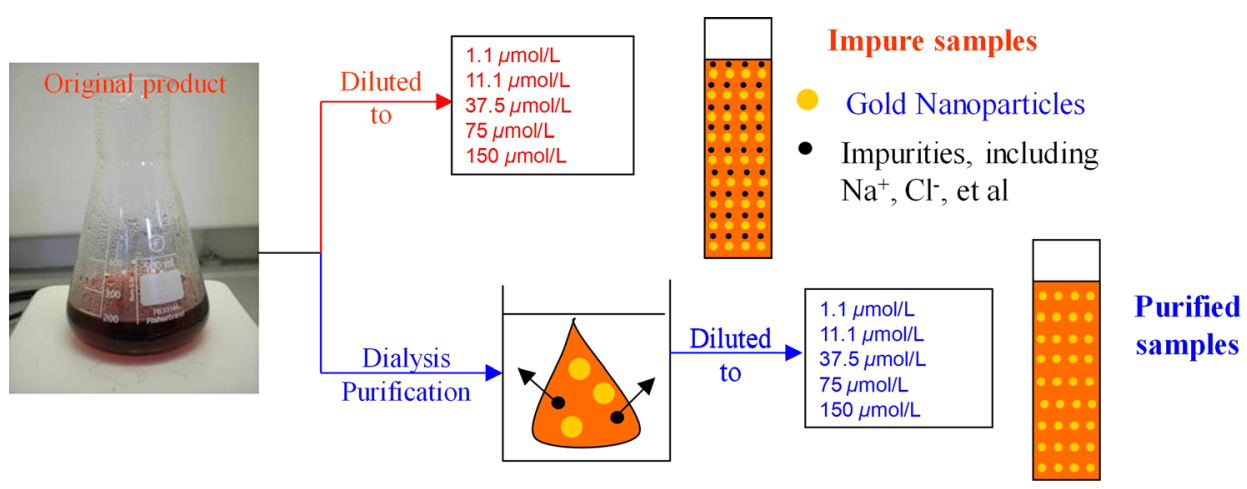

FIG. 7. The process of purification. Drawn from the description of Ref. 87. 
To eliminate the difference caused by the heating instruments. A separate experiment was conducted using the Kanzius machine in cooperation with the MD cancer center in Huston Texas, USA (see details in Section 3.4 in Ref. 87). It was demonstrated that purified nanoparticle dispersions produced very limited heat, in sharp contrast to impurified samples. Such a comparison clearly showed that the ionic contribution was much more pronounced than GNPs. Since the same samples were used in both transmission line wave guide and the Kanzius machine, and similar results were produced from both systems, it can be safely drawn that naked GNPs cannot be heated significantly by the electric field.

It has been argued that the interaction between ions and NPs could be significant. ${ }^{75}$ The argument was the heating effects reported in Ref. 54. To validate such a point, one can assume that the heating of nanofluids containing ions is originated from three parts, the ions $\left(P_{i}\right)$, the nanoparticles $\left(P_{n p}\right)$, and the interaction between the ions and nanoparticles $\left(P_{i-n p}\right)$, as below

$$
P=P_{i}+P_{n p}+P_{i-n p} .
$$

If the interaction between the ions and nanoparticles contributed considerably to the RF heating, then $P_{i-n p}$ shall be comparable or even larger than $P_{i}$ and $P_{n p}$. Unfortunately, such a phenomenon has not be observed in the literature..$^{27,28,87}$ The purified GNP dispersions did not show any heating, while impurified GNP dispersions and the supernatant fluid showed almost the same heating rates. Moreover, it is noted that in Ref. 54, the nanoparticles were actually super-paramagnetic nanoparticles, and that the heating method was mainly due to the magnetic heating. Consequently, it is difficult to judge how much heating effect was produced by GNPs. In addition, ionic solution could also be heated by magnetic field through the eddy current, which was demonstrated in Fig. 4 of Ref. 54. Seeing from the results (Fig. 4 of Ref. 54), the temperature rise of the mixture solution of $1 \mathrm{mM} \mathrm{NaCl}$ and $100 \mu \mathrm{M} \mathrm{Au}_{102}(\mathrm{pMBA})_{44}$ came from many sources. The role of the interaction between the ions and nanoparticles appeared not significant. Though further rigorous experiments were still needed to confirm such an observation, it is clear that the electric field heating was not responsible for the heating reported in Ref. 54.

\section{Limitations of the current heating models}

It is clear that most of the mechanisms proposed so far were basically based on the classical theories such as Mie theory, Joule heating, dielectric loss, electrophoretic loss, and even quantum effects, but none of them could rectify the controversies between the experiments and predictions.

For laser heating (IR, visible-light region, etc.), the heating effect could be very prominent as the wavelength is comparable to the periphery of nanoparticles. The Mie theory can be employed successfully to explain the dissipation of EM energy. For magnetic heating, the nanoparticles are normally ferromagnetic or ferrimagnetic and the heating mechanisms have been in large identified. The current controversies of electric field heating are likely multifolds, caused by both not-well controlled experiments and insufficient understanding on the heating mechanisms.

Actually, it is difficult to judge which experiment was conducted with sufficient accuracy. For instance, in Refs. 23 and 24, two key factors need to be clearly clarified: one is the field strength and the other is the impurities of the sample. Similarly, $\mathrm{Li}^{27}$ and $\mathrm{Liu}^{28}$ did not consider the effect of charged particles on the heating process. In consequence, their experiments could not exclude the possibility of heating effects due to charged particles. Although $\mathrm{Corr}^{46}$ considered charge influence, the accurate charge information on the particles was missing, and the electric field strength characterisation was also questionable. Generally, the power density is linearly proportional to the square of the electric field strength, but the result (Fig. 7 in Ref. 46) showed a linear dependence. In Collin's review, ${ }^{75}$ it was suggested that the particle size shall play an important role, and particles smaller than $10 \mathrm{~nm}$ would manifest a high heating effect. Unfortunately, there is still no systematic experiment to investigate the particle size effect free of impurities. It is noted that different instruments were utilized, which needs to be calibrated carefully to quantify the field strength in the sample. Up to now, the field strength produced in the Kanzius system still needs to be rigorously measured to quantitatively describe the heating effect.

As to the theoretical consideration, the Mie theory is ideally for spherical particles, but has difficulties in modeling roughed particles, particles of different shapes and the aggregation effect. For the electrophoretic model, it has difficulties in explaining the effect of low particle concentration, which was the case for most published studies, and the accurate knowledge of the viscosity under high particle concentration, especially for irregular-shaped particles, still present a challenge.

Clearly there are large discrepancies on the effect of nanoparticle under a RF field. As many in vitro studies already demonstrated that GNPs-incubated cells brought significant cell damage under RF radiation, while the control groups did not, one question has to be answered: what are the effects that caused such a phenomenon? Heating effect or anything else? If it was due to the heating, as analyzed above, why existing theory could not provide a satisfactory answer? Such a question was raised recently in a review work published in Science, Are Gold Clusters in RF Fields Hot or Not ${ }^{88}$ A few possibilities are explored below.

\section{Possibilities to increase the electric field heating rate}

It is worth mentioning here Hanson's work that there are a few optimal parameters to achieve the maximal heating rate. $^{76}$

For instance, multilayered nanoparticles may possibly give one extra freedom for controlling the heating property, see Fig. 8. For a single-layered particle, the field distribution inside the particle can be written as 


$$
\vec{E}(\vec{r})=\left\{\begin{array}{l}
\hat{r} E_{0}\left(-1-\frac{\varepsilon-\varepsilon_{1}}{\varepsilon+2 \varepsilon_{1}} \cdot \frac{2 R^{3}}{r^{3}}\right) \cos \theta+\hat{\theta} E_{0}\left(1-\frac{\varepsilon-\varepsilon_{1}}{\varepsilon+2 \varepsilon_{1}} \cdot \frac{2 R^{3}}{r^{3}}\right) \sin \theta \quad r>R \\
-\hat{z} E_{0} \frac{3 \varepsilon_{1}}{\varepsilon+2 \varepsilon_{1}} \quad 0 \leq r<R .
\end{array}\right.
$$

The electric field inside nanoparticles is uniformly distributed and dependent on the dielectric property. In multi-layered nanoparticles, however each layer owns different permittivities with varying size. Through changing the permittivity and the size of each layer, one has another freedom to optimize the heating effect. For instance, Hanson showed that the absorption cross section of coated nanoparticles was larger than those of bare nanoparticle (see Figs. 3 and 4 in Ref. 76). As most of nanoparticles are coated with ligand or other layers of medical, chemical, or biological functionalities, they shall behave more like multi-layered particles. In addition, the shape of nanoparticle makes significant difference to the heating effects. Nanoparticles with large aspect ratios are more likely to be heated, supported by both theoretical study $^{77}$ and experimental observation. ${ }^{80,89}$ Charged particles are still a viable way if the uptake of nanoparticles can take place, and electrophoretic phenomena can be expected in the cytoplasm. It appears possible to engineer nanoparticles with different layered-structures, morphologies, and charges that could achieve a good heating effect under a RF field.

From the electromagnetic aspect, it is understood that the EM frequency is also a dimension to explore to maximize the heating. Clearly the response of a medium to electromagnetic waves/fields varies significantly with the operating frequency, where electrons or dipoles follow the cyclic variation of an alternating field. As the dielectric properties are frequencydependent, a systematic study on the frequency effect is much needed. Normally, the dielectric property can be modelled as

$$
\varepsilon_{r}(\omega)=\varepsilon_{r}^{\prime}-j \varepsilon_{r}^{\prime \prime}=\varepsilon_{r \text { inf }}+\frac{\varepsilon_{r 0}-\varepsilon_{r i n f}}{1+j \omega \tau}-\frac{j \sigma_{0}}{\omega \varepsilon_{0}},
$$

where

$$
\left\{\begin{array}{l}
\varepsilon_{r}^{\prime}=\varepsilon_{r i n f}+\frac{\varepsilon_{r} 0-\varepsilon_{r \text { inf }}}{1+(\omega \tau)^{2}} \\
\varepsilon_{r}^{\prime \prime}=\frac{\left(\varepsilon_{r 0}-\varepsilon_{r \text { inf }}\right) \omega \tau}{1+(\omega \tau)^{2}}+\frac{\sigma_{0}}{\omega \varepsilon_{0}} \\
\sigma(\omega)=\frac{\left(\varepsilon_{r 0}-\varepsilon_{r \text { inf }}\right) \omega^{2} \varepsilon_{0} \tau}{1+(\omega \tau)^{2}}+\sigma_{0},
\end{array}\right.
$$
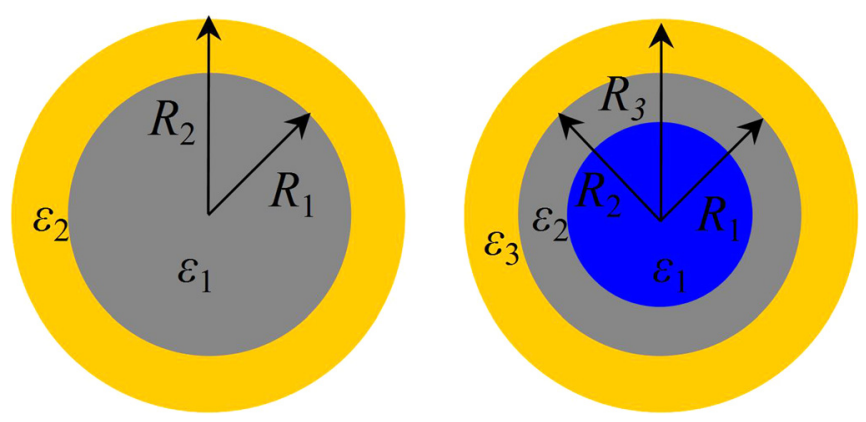

FIG. 8. Examples of multilayered nanoparticles. $\sigma_{0}$ is the ionic conductivity (or DC conductivity), $\varepsilon_{r_{0}}$ is the static permittivity, $\varepsilon_{r \text { inf }}$ is the optical permittivity, $\tau$ is the relaxation time, and $\omega$ is the angular frequency. The temperature rise of a medium can be calculated using

$$
\Delta T=\frac{\sigma(\omega) \cdot|\vec{E}|^{2} \cdot t}{2 \rho \cdot C},
$$

where $|\vec{E}|$ is the electric field strength in the medium, $t$ is the heating time, $\rho$ is the local density of the medium, and $C$ is the specific heat capacity. As an example, the conductivitydependent temperature rise of $\mathrm{NaCl}$ solution at different frequencies is illustrated in Fig. 9. Configuration of this experimental was described in Fig. 14 of Ref. 86. It clearly shows that the peak temperature rise increases with the increase of EM frequency. The optimized ionic conductivity is also shifted to high values. However, caution is needed on the possible reduction in the penetration depth at high EM frequencies.

From the biological consideration, it shall differentiate possible differences between the macroscopic effect and the local effect. Here, the macroscopic effect is referred to be the increase of global temperature in a sample, and the local effect refers to the temperature field surrounding heated nanoparticles, which is effective at the cell level. From a macroscopic view, the heating effect has to be high enough to increase the bulk temperature of the fluid to be detected by temperature sensors. It is possible that the temperature in the vicinity of the GNPs is high enough to damage the membrane of cancer cells, though the bulk temperature rise is still negligible. For instance, for a single cell, the energy needed to increase from a normal human body temperature to $42{ }^{\circ} \mathrm{C}$ is approximately $6.0 \times 10^{-13} \mathrm{~J}$, assuming the diameter of a cell is $20 \mu \mathrm{m}$. Suppose each cancer cell has 10 nanoparticles attached on the membrane. Then, each particle only needs to

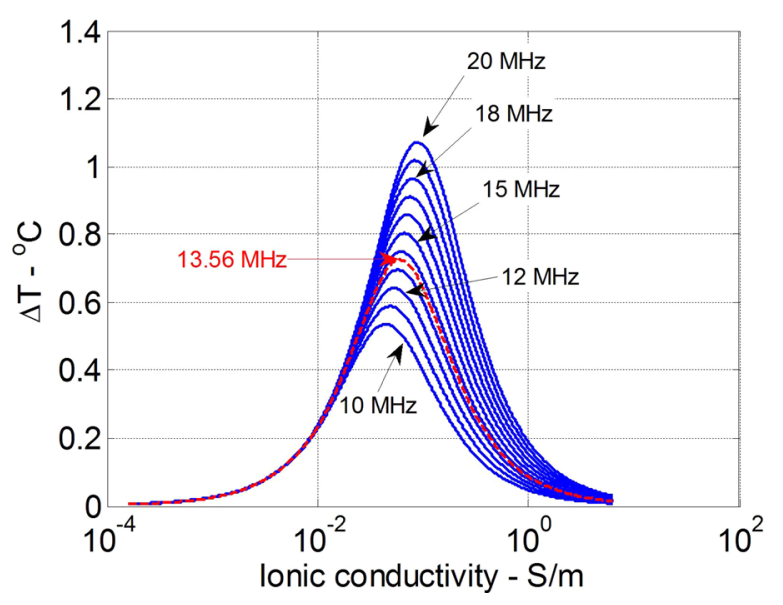

FIG. 9. Conductivity dependent temperature rise. 
produce $6.0 \times 10^{-14} \mathrm{~J}$ in a duration of $10-30 \mathrm{~min}$. Based on the energy dissipation of a single particle

$$
\Delta E=\frac{\sigma(\omega) \cdot|\vec{E}|^{2} \cdot t}{2} \cdot \frac{4 \pi}{3} d^{3},
$$

with a few usual assumptions of $\sigma=1 \mathrm{~S} / \mathrm{m},|\vec{E}|=400 \mathrm{~V} / \mathrm{m}$, $t=30 \mathrm{~min}, d=20 \mathrm{~nm}$, it gives $\Delta E \approx 1 \times 10^{-14} \mathrm{~J}$, which is on the same order of $6.0 \times 10^{-14} \mathrm{~J}$. In addition, it is known that nanoparticles have a tendency to accumulate around the cells due to the targeting, exhibiting an anisotropic distribution. The local nanoparticle concentration therefore is much higher than the bulk value. As the temperature increase is nearly proportional to the nanoparticle concentration, it is highly likely that strong localized heating can be produced at the cell level. Still using the same example before, if 10 times more nanoparticles were accumulated on the membrane or into the cell, sufficient heating could be produced to raise the temperature above $42{ }^{\circ} \mathrm{C}$. Clearly, accurate determination of local temperature and local nanoparticle concentration is essential to advance our understanding on the RFnanoparticle heating, which however deserves further study.

In addition, since magnetic particle may involve magnetic hysteresis to cause EM energy dissipation. There may have certain materials with electrical hysteresis properties that can increase the electric field heating rate. Reported results of such material can be found in Refs. 90-92. As electric fields are more likely to be focused on a small area, excellent electrical hysteresis property may be suitable for electric field heating. Finally, the synergic effect from different mechanisms shall be noted, which may produce more heating than the individual element.

\section{CONCLUSION}

This review paper presented an overview on three methods of electromagnetic heating of nanomaterials: laser heating, magnetic field heating, and electric field heating at RF spectrum, with the focus on the last one. It is shown that the mechanisms of IR and magnetic heating are well understood, while the electric field heating is still of great controversy. The controversies consist of three aspects: (1) Can nanomaterials be heated or not by RF; (2) by what mechanisms that nanomaterials can dissipate electromagnetic energy; and (3) is the cell death caused by the hyperthermia effect?

From the analysis, it can be concluded that electric field at $13.56 \mathrm{MHz}$ along cannot produce significant heating effect on naked dilute gold nanoparticles. Considering many in vitro studies, which demonstrated that GNPs-incubated cancer cells were liable to RF radiation, it is still difficult to judge if the biological effect was caused by hyperthermia. Further, more comprehensive experiments from both biological and physical disciplinaries are needed to clarify such a puzzle. There may exist strong localized heating due to the concentration of nanoparticles around the targeting cells, which may be responsible for cell killing. In addition, the influence of particle materials and morphology on RF heating is still unclear, there shall exists optimized nanoparticles suitable for RF hyperthermia applications.
A few areas are proposed for further investigation to advance our understanding on effective RF heating, namely, (i) nanoparticle structure and properties, (ii) EM frequency, and (iii) localized heating effect.

\section{ACKNOWLEDGMENTS}

This work was supported by the National Nature Science Foundation of China under the Contract No. 61401031, and the fund from Shunde Government, Guangdong Province, China, under the Contract No. 20140401.

${ }^{1}$ Nanotechnology Standards, edited by V. Murashov and J. Howard (Springer, New York, 2011).

${ }^{2}$ E. L. Wolf, Nanophysics and Nanotechnology: An Introduction to Modern Concepts in Nanoscience (Wiley-VCH Verlag GmbH \& Co. KGaA, Weinheim, 2006).

${ }^{3}$ Nanoparticle Technology for Drug Delivery, edited by R. B. Gupta and U. B. Kompella (Taylor \& Francis Group, New York, 2006).

${ }^{4}$ E. Torres-Chavolla, R. J. Ranasinghe, and E. C. Alocilja, IEEE Trans. Nanotechnol. 9, 533-538 (2010).

${ }^{5}$ E. Hutter and D. Maysinger, Microsc. Res. Tech. 74, 592-604 (2011).

${ }^{6}$ M. Xie, H. Shi, K. Ma, H. Shen, B. Li, S. Shen, X. Wang, and Y. Jin, J. Colloid Interface Sci. 395, 306-314 (2013).

${ }^{7}$ S. Parveen, R. Misra, and S. K. Sahoo, Nanomed.: Nanotechnol. Biol. Med. 8, 147-166 (2012).

${ }^{8}$ S. Naahidi, M. Jafari, F. Edalat, K. Raymond, A. Khademhosseini, and P. Chen, J. Controlled Release 166, 182-194 (2013).

${ }^{9}$ S. Tan, X. Li, Y. Guo, and Z. Zhang, Nanoscale 5, 860-872 (2013).

${ }^{10}$ L. C. Kennedy, L. R. Bickford, N. A. Lewinski, A. J. Coughlin, Y. Hu, E. S. Day, J. L. West, and R. A. Drezek, Small 7, 169-183 (2011).

${ }^{11}$ S. Jain, D. G. Hirst, and J. M. O'Sullivan, Br. J. Radiol. 85, 101-113 (2012).

${ }^{12}$ M. E. Davis, Z. Chen, and D. M. Shin, Nat. Rev. Drug Discovery 7, 771-782 (2008).

${ }^{13}$ P. K. Jain, W. Qian, and M. A. El-Sayed, J. Am. Chem. Soc. 128, 2426-2433 (2006).

${ }^{14}$ X. Liu, Q. Dai, L. Austin, J. Coutts, G. Knowles, J. Zou, H. Chen, and Q. Huo, J. Am. Chem. Soc. 130, 2780-2782 (2008).

${ }^{15}$ N. Karra and S. Benita, Curr. Drug Metab. 13, 22-41 (2012).

${ }^{16}$ W. Shia, Y. Sahoo, and M. T. Swihart, Colloids Surf., A 246, 109-113 (2004).

${ }^{17}$ R. W. Y. Habash, R. Bansal, D. Krewski, and H. T. Alhafid, Crit. Rev. Biomed. Eng. 34, 459-489 (2006).

${ }^{18}$ B. Hildebrandt, P. Wust, O. Ahlers, A. Dieing, G. Sreenivasa, T. Kerner, R. Felix, and H. Riess, Crit. Rev. Oncol./Hematol. 43, 33-56 (2002).

${ }^{19}$ M. Palazzi, S. Maluta, S. Dall'Oglio, and M. Romano, Tumori 96, 902-910 (2010).

${ }^{20}$ S. Tatli, Ü. Tapan, P. R. Morrison, and S. G. Silverman, Diagn. Interventional Radiol. 18, 508-516 (2012).

${ }^{21}$ D. Haemmerich and P. F. Laeseke, Int. J. Hyperthermia 21, 755-760 (2005).

${ }^{22}$ C. J. Gannon, C. R. Ratra, R. Bhattacharya, P. Mukherjee, and S. A. Curley, J. Nanobiotechnol. 6(2), 1-9 (2008).

${ }^{23}$ J. Cardinal, J. R. Klune, E. Chory, G. Jeyabalan, J. S. Kanzius, M. Nalesnik, and D. A. Geller, Surgery 144, 125-132 (2008).

${ }^{24}$ C. H. Moran, S. M. Wainerdi, T. K. Cherukuri, C. Kittrell, B. J. Wiley, N. W. Nicholas, S. A. Curley, J. S. Kanzius, and P. Cherukuri, Nano Res. 2, 400-405 (2009).

${ }^{25}$ C. J. Gannon, P. Cherukuri, B. I. Yakobson, L. Cognet, J. S. Kanzius, C. Kittrell, R. B. Weisman, M. Pasquali, H. K. Schmidt, R. E. Smalley, and S. A. Curley, Cancer 110, 2654-2665 (2007).

${ }^{26}$ D. E. Kruse, D. N. Stephens, H. A. Lindfors, E. S. Ingham, E. E. Paoli, and K. W. Ferrara, IEEE Trans. Biomed. Eng. 58, 2002-2011 (2011).

${ }^{27}$ D. Li, Y. S. Jung, S. Tan, H. K. Kim, E. Chory, and D. A. Geller, J. Colloid Interface Sci. 358, 47-53 (2011).

${ }^{28}$ X. Liu, H.-J. Chen, C. Chen, C. Parini, and D. Wen, Nanoscale 4, 3945-3953 (2012).

${ }^{29}$ H.-J. Chen and D. Wen, Nanomedicine 8, 215-222 (2013).

${ }^{30}$ F. H. Ghahremani, A. Sazgarnia, M. H. Bahreyni-Toosi, O. Rajabi, and A. Aledavood, Int. J. Hyperthermia 27, 625-636 (2011). 
${ }^{31}$ K. Mollazadeh-Moghaddam, B. V. Moradi, R. Dolatabadi-Bazaz, M. Shakibae, and A. R. Shahverdi, Avicenna J. Med. Biotechnol. 3, 195-200 (2011).

${ }^{32}$ A. M. Gobin, M. H. Lee, and N. J. Halas, Nano Lett. 7, 1929-1934 (2007).

${ }^{33}$ M. Mehdizadeh, Microwave/RF Applicators and Probes for Material Heating Sensing and Plasma Generation (Elsevier, Oxford, 2010).

${ }^{34}$ J. N. Burghartz and B. Rejaei, IEEE Trans. Electron Devices 50, 718-729 (2003).

${ }^{35}$ J. B. Goodenough, IEEE Trans. Magn. 38, 3398-3408 (2002).

${ }^{36}$ J. Lee, Y.-K. Hong, W. Lee, G. S. Abo, J. Park, W.-M. Seong, and W.-K. Ahn, J. Appl. Phys. 113, 073909 (2013).

${ }^{37}$ E. C. Dreaden, A. M. Alkilany, X. Huang, C. J. Murphy, and M. A. ElSayed, Chem. Soc. Rev. 41, 2740-2779 (2012).

${ }^{38}$ N. Khlebtsov and L. Dykman, Chem. Soc. Rev. 40, 1647-1671 (2011).

${ }^{39}$ P. M. Tiwari, K. Vig, V. A. Dennis, and S. R. Singh, Nanomaterials 1, 31-63 (2011)

${ }^{40}$ S. A. Curley, P. Cherukuri, K. Briggs, C. R. Patra, M. Upton, E. Dolson, and P. Mukherjee, J. Exp. Ther. Oncol. 7, 313-326 (2008).

${ }^{41}$ E. Araya, I. Olmedo, N. G. Bastus, S. Guerrero, V. F. Puntes, E. Giralt, and M. J. Kogan, Nanoscale Res. Lett. 3, 435-443 (2008).

${ }^{42}$ E. S. Glazer, C. Zhu, K. L. Massey, C. Shea Thompson, W. D. Kaluarachchi, A. N. Hamir, and S. A. Curley, Clin. Cancer Res. 16, 5712-5721 (2010).

${ }^{43}$ E. S. Glazer, K. L. Massey, C. Zhu, and S. A. Curley, Surgery 148, 319-324 (2010).

${ }^{44}$ E. S. Glazer and S. A. Curley, Cancer 116, 3285-3293 (2010).

${ }^{45}$ M. Raoof, C. Zhu, W. D. Kaluarachchi, and S. A. Curley, Int. J. Hyperthermia 28, 202-209 (2012).

${ }^{46}$ S. J. Corr, M. Raoof, Y. Mackeyev, S. Phounsavath, M. A. Cheney, B. T. Cisneros, M. Shur, M. Gozin, P. J. McNally, L. J. Wilson, and S. A. Curley, J. Phys. Chem. C 116, 24380-24389 (2012).

${ }^{47}$ B. H. San, S. H. Moh, and K. K. Kim, Int. J. Hyperthermia 29, 99-105 (2013).

${ }^{48}$ P. D. Vedova, M. Ilieva, V. Zhurbenko, R. Mateiu, A. Faralli, M. Dufva, and O. Hansen, "Gold nanoparticle-based sensors activated by external radio frequency fields," Small 11, 248 (2015).

${ }^{49}$ A. Gupta, R. S. Kane, and D.-A. Borca-Tasciuc, J. Appl. Phys. 108, 064901 (2010).

${ }^{50}$ T. L. Kline, Y.-H. Xu, Y. Jing, and J.-P. Wang, J. Magn. Magn. Mater. 321, 1525-1528 (2009).

${ }^{51}$ I. Marcos-Campos, L. Asín, T. E. Torres, C. Marquina, A. Tres, M. R. Ibarra, and G. F. Goya, Nanotechnology 22, 205101 (2011).

${ }^{52}$ V. S. Kalambur, E. K. Longmire, and J. C. Bischof, Langmuir 23, 12329-12336 (2007)

${ }^{53}$ E. Lima, Jr., E. De Biasi, M. Vasquez Mansilla, M. E. Saleta, M. Granada, H. E. Troiani, F. B. Effenberger, L. M. Rossi, H. R. Rechenberg, and R. D. Zysler, J. Phys. D: Appl. Phys. 46, 045002 (2013).

${ }^{54}$ R. S. McCoy and S. Choi, ACS Nano 7(3), 2610-2616 (2013).

${ }^{55}$ A. Wijaya, K. A. Brown, J. D. Alper, and K. Hamad-Schifferli, J. Magn. Magn. Mater. 309, 15-19 (2007).

${ }^{56}$ R. Ghosh, L. Pradhan, Y. Priyabala Devi, S. S. Meena, R. Tewari, A. Kumar, S. Sharma, N. S. Gajbhiye, R. K. Vatsa, B. N. Pandey, and R. S. Ningthoujam, J. Mater. Chem. 21, 13388-13398 (2011).

${ }^{57}$ I. Hilger, W. Andra, R. Hergt, R. Hiergeist, H. Schubert, and W. A. Kaiser, Radiology 218, 570-575 (2001).

${ }^{58}$ D. H. Kim, D. E. Nikles, D. T. Johnson, and C. S. Brazel, J. Magn. Magn. Mater. 320, 2390-2396 (2008).

${ }^{59}$ G. D. Bothun and M. R. Preiss, J. Colloid Interface Sci. 357(1), 70-74 (2011).

${ }^{60}$ L. R. Hirsch, R. J. Stafford, J. A. Bankson, S. R. Sershen, B. Rivera, R. E. Price, J. D. Hazle, N. J. Halas, and J. L. West, Proc. Natl. Acad. Sci. U. S. A. 100(23), 13549-13554 (2003).
${ }^{61}$ S. Hormeño, P. Gregorio-Godoy, J. Pérez-Juste, L. M. Liz-Marzán, B. H. Juárez, and J. R. Arias-Gonzalez, Small 10, 376-384 (2014).

${ }^{62}$ A. Siems, S. A. L. Weber, J. Boneberg, and A. Plech, New J. Phys. 13, 043018 (2011).

${ }^{63}$ N. Kojic, E. M. Pritchard, H. Tao, M. A. Brenckle, J. P. Mondia, B. Panilaitis, F. Omenetto, and D. L. Kaplan, Adv. Funct. Mater. 22(18), 3793-3798 (2012).

${ }^{64}$ N. N. Nedyalkova, S. E. Imamovaa, P. A. Atanasova, R. A. Toshkovab, E. G. Gardevab, L. S. Yossifovab, M. T. Alexandrovb, and M. Obarac, Appl. Surf. Sci. 257, 5456-5459 (2011).

${ }^{65}$ X. Liu, H.-J. Chen, X. Chen, Y. Alfadhl, C. Parini, and D. Wen, J. Appl. Phys. 113, 074902 (2013).

${ }^{66}$ V. P. Pattani and J. W. Tunnell, Lasers Surg. Med. 44(8), 675-684 (2012).

${ }^{67}$ A. Kyrsting, P. M. Bendix, D. G. Stamou, and L. B. Oddershede, Nano Lett. 11, 888-892 (2011).

${ }^{68}$ D. Wen, Int. J. Hyperthermia 25, 533-541 (2009).

${ }^{69}$ O. Ekici, R. K. Harrison, N. J. Durr, D. S. Eversole, M. Lee, and A. BenYakar, J. Phys. D: Appl. Phys. 41, 185501 (2008).

${ }^{70}$ V. K. Pustovalov, Chem. Phys. 308, 103-108 (2005).

${ }^{71}$ J. H. Hodak, A. Henglein, and G. V. Hartland, J. Chem. Phys. 112, 5942 (2000).

${ }^{72}$ M. R. Arnfield, J. Tulip, M. Chetner, and M. S. McPhee, Med. Phys. 16(4), 602-608 (1989).

${ }^{73}$ I. Hilger, R. Hergt, and W. A. Kaiser, IEE Proc. - Nanobiotechnol. 152, 33-39 (2005).

${ }^{74}$ Q. A. Pankhurst1, J. Connolly, S. K. Jones, and J. Dobson, J. Phys. D: Appl. Phys. 36, R167-R181 (2003).

${ }^{75}$ C. B. Collins, R. S. McCoy, B. J. Ackerson, G. J. Collins, and C. J. Ackerson, Nanoscale 6, 8459-8472 (2014).

${ }^{76}$ G. W. Hanson and S. K. Patch, J. Appl. Phys. 106, 054309 (2009).

${ }^{77}$ G. W. Hanson, R. C. Monreal, and S. P. Apell, J. Appl. Phys. 109, 124306 (2011).

${ }^{78}$ E. Sassaroli, K. C. P. Li, and B. E. O’Neill, J. Phys. D: Appl. Phys. 45, 075303 (2012).

${ }^{79}$ J. A. Pearce and J. E. Cook, "Heating mechanisms in gold nanoparticles at radio frequencies," in 33rd Annual International Conference of the IEEE EMBS, Boston, Massachusetts, USA, 30 August-3 September 2011.

${ }^{80}$ A. Mashal, B. Sitharaman, X. Li, and P. K. Avti, IEEE Trans. Biomed. Eng. 57(8), 1831-1834 (2010)

${ }^{81}$ D. Li, Y. S. Jung, H. K. Kim, J. Chen, D. A. Geller, M. V. Shuba, S. A. Maksimenko, S. Patch, E. Forati, and G. W. Hanson, IEEE Trans. Biomed. Eng. 59, 3468-3474 (2012).

${ }^{82}$ S. Ganguly, S. Sikdar, and S. Basu, Powder Technol. 196(3), 326-330 (2009).

${ }^{83}$ W. A. Curtin, R. C. Spitzer, N. W. Aschcroft, and A. J. Sievers, Phys. Rev. Lett. 54, 1071 (1985).

${ }^{84}$ B. P. Devaty and A. J. Sievers, Phys. Rev. B 41, 7421 (1990).

${ }^{85}$ S. Campione, S. M. Adams, R. Ragan, and F. Capolino, Opt. Express 21(7), 7957-7973 (2013).

${ }^{86}$ X. Liu, H.-J. Chen, X. Chen, Y. Alfadhl, J. Yu, and D. Wen, J. Appl. Phys. 115, 094903 (2014).

${ }^{87}$ X. Liu, "Exploration of electromagnetic waves with nanoscale materials," Ph.D. thesis (Queen Mary University of London, 2012).

${ }^{88}$ H. K. Kim, G. W. Hanson, and D. A. Geller, Science 340, 441-442 (2013).

${ }^{89}$ M. V. Shuba, G. Ya. Slepyan, S. A. Maksimenko, and G. W. Hanson, J. Appl. Phys. 108, 114302 (2010)

${ }^{90}$ Z. Surowiak, J. Brodacki, and H. Zajosz, Rev. Sci. Instrum. 49, 1351-1354 (1978)

${ }^{91}$ M. Wegener, Rev. Sci. Instrum. 79, 106103 (2008).

${ }^{92}$ J. Wang, T. Yang, K. Wei, and Y. Yao, Appl. Phys. Lett. 102, 152907 (2013). 